\title{
Combining landslide susceptibility maps and rainfall thresholds using a matrix approach
}

\author{
Benni THIEBES ${ }^{1}$, Shibiao $\mathrm{BAI}^{2,3,4,5^{*}}$, Yanan $\mathrm{XI}^{2,3}$, Thomas GLADE ${ }^{1}$, Rainer BELL ${ }^{1}$ \\ ${ }^{1}$ Institute for Geography and Regional Research, University of Vienna, Austria Hungary \\ ${ }^{2}$ Key Laboratory of Virtual Geographic Environment (Nanjing Normal University), Ministry of Education, \\ Nanjing, 210023, China \\ ${ }^{3}$ Jiangsu Center for Collaborative Innovation in Geographical Information Resource Development and \\ Application, Nanjing Normal University, 210023, Nanjing, China \\ ${ }^{4}$ Institute of Mountain Hazards and Environment, Chinese Academy of Sciences, Chengdu, 610041, \\ China \\ ${ }^{5}$ Center for Excellence in Tibetan Plateau Earth Sciences, Chinese Academy of Sciences, 100101, Beijing, \\ China
}

Received 2 October 2017; Revised 25 October 2017 ; Accepted 30 October 2017

*Correspondence to: Shibiao BAI, e-mail: shibiaobai@njnu.edu.cn

\begin{abstract}
On the regional scale, investigations on future landslide can broadly be distinguished in spatial or temporal analyses, i.e. landslide susceptibility or hazard maps, and landslide triggering rainfall thresholds. Even though both approaches have its uses e.g. in spatial planning, risk management and early warning, they also have limitations. Susceptibility and hazard maps do not contain information on when landslides will be triggered, while rainfall thresholds give no detailed indication on where a landslide might take place. The combination of spatial and temporal landslide research remains a complex issue and no ready-to-use methodology for combined spatiotemporal landslide analyses is presently available. In our study, we present a simple matrix approach to combine spatial and temporal landslide probabilities and highlight its application for a case study in the Wudu region, China. Landslide susceptibility mapping is based on a previous study involving logistic regression; the analysis of rainfall threshold was carried out applying the daily rainfall model. A $4 \times 4$ matrix was used to combine and reclassify the spatial and temporal landslide information. The results are then plotted on a map to highlight the susceptibility for rainfall events with varying likelihood of triggering landslides.
\end{abstract}

\section{KEYWORDS}

Landslides; susceptibility mapping; rainfall thresholds; matrix approach; China 


\section{Introduction}

Landslides are an important geomorphological hazard and are responsible for significant damage to infrastructure as well as loss of lives. Petley (2012) reported an annual death toll of approximately 1600 due to non-seismic landslide events alone, the majority of these occurring in Asia. Yin et al. (2009) estimated an average of 700 to 900 landslide related fatalities per year for China. In particular large seismic shocks can result in substantial landslide activity. For the 2008 Wenchuan earthquake (magnitude M7.8), more than 20,000 landslide were reported and attributed to a third of the approximately 60,000 fatalities (Huang and Li, 2009). Consequently, the prediction of future landslides in space and time is crucial and should be fostered.

Landslide investigations generally concentrate on either the local scale, i.e. single slopes, or the regional scale, i.e. larger regions (Thiebes, 2012). While the former scale is a focus of engineering geology and related disciplines, the latter scale has intensively been worked on by geomorphologists and geographers. The basis of most regional scale landslide studies are landslide inventories, i.e. maps showing the location of landslides within the region. These can be used to compute landslide susceptibility maps depicting the spatial probability of slope failures using a wide range of approaches utilising Geographic Information Systems (GIS). The methodologies to estimate landslide susceptibility can broadly be divided into heuristic, statistic and deterministic approaches (Soeters and Van Westen, 1996; Van Westen et al., 2006). Ordinary logistic regression is one of the methods that has been used extensively to map landslide susceptibility (e.g. Atkinson and Massari, 1998; Süzen and Doyuran, 2004; Akgün and Bulut, 2007; Greco et al., 2007; Bai et al., 2009, 2010b, 2012). Matrix approaches have also been used to produce regional scale landslide susceptibility maps (DeGraff and Romesburg, 1980; Fernández et al., 1999, 2003; Irigaray et al., 2007; De Graff et al., 2012). A main shortcoming of susceptibility maps is the lack of information on the temporal probability of landslides as well as on the magnitude of potential slope failures.

The regional scale analysis of the temporal probability of landslides strongly relies on the assessment of landslide triggering rainfall thresholds. This field of research has essentially been established by the works of Caine (1980) who put forward the first relationship between the intensity and duration of rainfall events and the triggering of landslides. Since then, many other researchers have established critical rainfall characteristics by the same methodology (Jakob et al., 2006; Matsushi and Matsukura, 2007; Crosta and Frattini, 2008; Guzzetti et al., 2008; Capparelli et al., 2009; Cepeda et al., 2010; Saito et al., 2010). Other empirical thresholds have been determined based on antecedent rainfall (Sorriso-Valvo et al., 1994), daily rainfall (Crozier, 1999; Glade, 2000) and event rainfall (Bell and Maud, 2000), cumulative event rainfall (Canuti et al., 1985; Corominas and Moya, 1999), cumulative event rainfall and event duration (Innes, 1983; Wilson et al., 1992; Zêzere and Rodriguez, 2002), and thresholds based on mean annual precipitation and normalised rainfall (Giannecchini, 2005; Sengupta et al., 2009). Over the past years, a wide range of critical rainfall thresholds have been developed and an extensive overview is available on the website of the Italian Research Institution IRPI (rainfallthresholds.irpi.cnr.it). It should also be noted that regional scale landslide early warning systems, e.g. in Hong Kong (Yu et al., 2004), Seattle (Chleborad et al., 2008) and Italy (Rossi et al., 2012), rely on rainfall thresholds for alerting civil protection and the general public.

At present, there is no general consensus on how landslide susceptibly maps and landslide triggering rainfall thresholds should be combined. However, a map combining both spatial and temporal landslide probabilities could aid spatial planning, civil protection agencies and the general public to deal with landslide hazards. In this paper, we present a straightforward matrix approach to combine a landslide susceptibility map and landslide triggering rainfall thresholds. To highlight our approach, we utilise a landslide susceptibility 
map created using logistic regression (Bai et al., 2013a) and rainfall thresholds established using the daily rainfall model (Bai et al., 2013b). Our approach combines spatial and temporal landslide occurrence probabilities using a simple $4 \times 4$ matrix to create a combined map; however, the method could easily be modified to accommodate different numbers of combination classes. The study area of our investigations is the Wudu region in China's Gansu province, an area that is substantially affected by landslide and frequently suffers landslide losses.

\section{Matrix approaches in landslide hazard and risk studies}

Matrix approaches have been used for landslide susceptibility, hazard and risk studies in various research applications. Frequently, matrixes have been utilised to combine different aspects of landslide hazards with the aim to derive a new index value which can be used for further analysis or to aid decision-making on landslide risk management. Moreover, matrix approaches have been highlighted as a helpful tool to harmonise existing landslide hazard information available in different countries and territories. One such example was provided by the AdaptAlp project (2011) which aimed for a comparison, evaluation, harmonisation and the improvement of different methods of hazard mapping. Here, a matrix approach was proposed to combine spatial and temporal probabilities of landslide processes to receive a unified qualitative probability.

Matrix approaches have often been employed to determine a basic risk index by combining hazards and consequences. A hazard-consequence matrix approach was proposed by Chowdhury and Flentje (2003) to provide a qualitative estimation of landslide risks. The authors note that the hazard may thus be evaluated separately from the consequence based on site inspections. Moreover, consequences may be assessed separately for loss of life and economic losses. Kjekstad (2007) proposed a similar matrix approach to carry out preliminary landslide risk assessment in particular for developing countries. Therein, three hazard classes from low to high are combined with three consequence classes. Consequence classes are based on a complex scoring system which takes into account e.g. the number of dwellings, the existence of critical infrastructure and life lines. The resulting risk index values range from one to five and aim to assist the prioritisation of high risk areas. Similar qualitative risk evaluations based on the combination of the likelihood of landslides and the potential consequences have been widely used by scientists (Ko Ko et al., 2004a, 2004b) and practitioners and have been included in respective guidelines (Kohler et al., 2004; Tonkin \& Taylor Ltd, 2006).

Another field of applications for matrixes in landslide studies focuses on describing the hazard by combining the intensity of the processes with the occurrence probabilities. The most prominent matrix approach based on this concept was put forward by the Swiss Federal Office for the Environment (BUWAL) and combines the intensity and occurrence probability or recurrence intervals of hazard processes including rockfalls, landslides, and avalanches (Latelin, 1997; Bundesamt für Umwelt Wald und Landschaft, 1998). In the BUWAL framework for hazard assessments, class boundaries of intensities and occurrence probabilities are determined by quantitative values such as kinetic energy (rockfalls), pressure (avalanches), thickness of mobilised material (debris flows) and movement speed (landslides). However, to make the methodology more approachable by practitioners and to ease its use for the prioritisation of counter measures, intensity and recurrence intervals are rather included as qualitative classes (i.e. low, medium, high). The resulting hazard index values are then plotted on a map to aid spatial planning by restricting building activities to areas with low or medium hazard values (Raetzo H. et al., 2002); for the latter certain building codes have to be respected. The BUWAL approach has also been used by other researchers, as well as regional administration dealing with landslides and other natural hazards (SafeLand Project, 2010; Paramount Project, 2012).

Additionally, matrixes have been employed to combine landslide susceptibility maps with information on the likelihood of their occurrence. 
One such example was provided by researchers in France (Thiery et al., 2006; Thiery, 2007). After estimating regional landslide susceptibility using a statistical bivariate weight of evidence approach, the occurrence probability was assed using a deterministic landslide model calculating safety factors. The results were then combined to receive a new hazard index value which aimed to better describe the landslide hazard conditions in the region than the two input model results alone. In another study, Bell et al. (2014) used two different $4 \times 4$ matrix approach to combine landslide susceptibility classes with hydro-meteorological index values to receive warning classes to be included in the national scale early warning system for shallow landslides and debris flows in Norway. Their results showed that the combined warning classes improved warning procedures significantly.

Recently, matrix approaches have also been utilised in landslide studies using satellite-based InSAR (Interferometric Synthetic Aperture Radar), in particular for the updating of existing landslide inventories and hazard maps. Cigna et al. (2012) acquired information on the state of activity as well as on the intensity of landslide movements for a pre-existing inventory of slope movements based on the PSI approach (Permanent Scatterer Interferometry). The results are then combined in a matrix to yield updated information on the state of landslide activity (i.e. active, reactivated, stabilised, dormant). For newly detected slope movements, i.e. landslide not contained in the existing landslide inventories, the state of activity is derived based on a matrix combining historic PSI analyses results with more recent data. Another example of a matrix approach in landslide-focused InSAR research was presented by Lu et al. (2014). Here, an existing landslide inventory that included information on the intensity of the processes derived from geometrical properties of the slope movements was combined with InSAR-based measurements of the displacement. The resulting new intensity classes are then integrated in a risk assessment and an estimation of potential economic losses.

\section{Study area}

China is one of the countries with the world's most serious geological disasters and experiences high economic losses every year. For the period from 2006 to 2008, a total number of 154,748 geological disasters were recorded by the China Institute of Geo-Environment Monitoring of which 118,351 were landslide-related, thus accounting for approximately $76 \%$ (China Geological Survey Bureau of Statistics, 2008). The annual direct economic damage of landslides has been estimated to be approximately 10 billion RMB (approximately US- $\$ 1.3$ billion) in addition to 700 to 900 fatalities per year (Yin, 2009). These numbers strikingly underline the importance of spatial and temporal landslide predictions, hazard and risk analyses, and disaster prevention measures.

The study area of this research is the Wudu region in western China (Fig. 1). It covers an area of $4,683 \mathrm{~km}^{2}$ and belongs to the prefecture-level city of Longnan in Gansu province. The Wudu region in Gansu province is a hot-spot of landslide activity (Scheidegger and Ai, 1987; Bai et al., 2010a, 2012) and was severely affected by the 2008 Wenchuan earthquake which caused hundreds slope failures (Cui et al., 2009; Chigira et al., 2010; Bai et al., 2013a). In addition, the earthquake deteriorated the area and made it more susceptible for future landslides (Jiao and Wang, 2010). Such secondary hazards are a major concern for local and regional decision-makers who require reliable information on current and future hazard conditions. The geological structure is dominated by the southern Qinling fold system. During the geologically recent Yenshan and Himalayan crustal movements, uplift and complex faulting of the region took place, resulting in widespread valley incision and undercutting of the slopes (Derbyshire et al., 1999). Current uplift rates in the study area are high and enhance geomorphological activity (Chen et al., 2006). The lithology of the study area consists of soft and erodible formations which are primarily marine metamorphic and carbonate rocks. Elevations in the study area range from $600 \mathrm{~m}$ to over $3500 \mathrm{~m}$ a.m.s.l. 


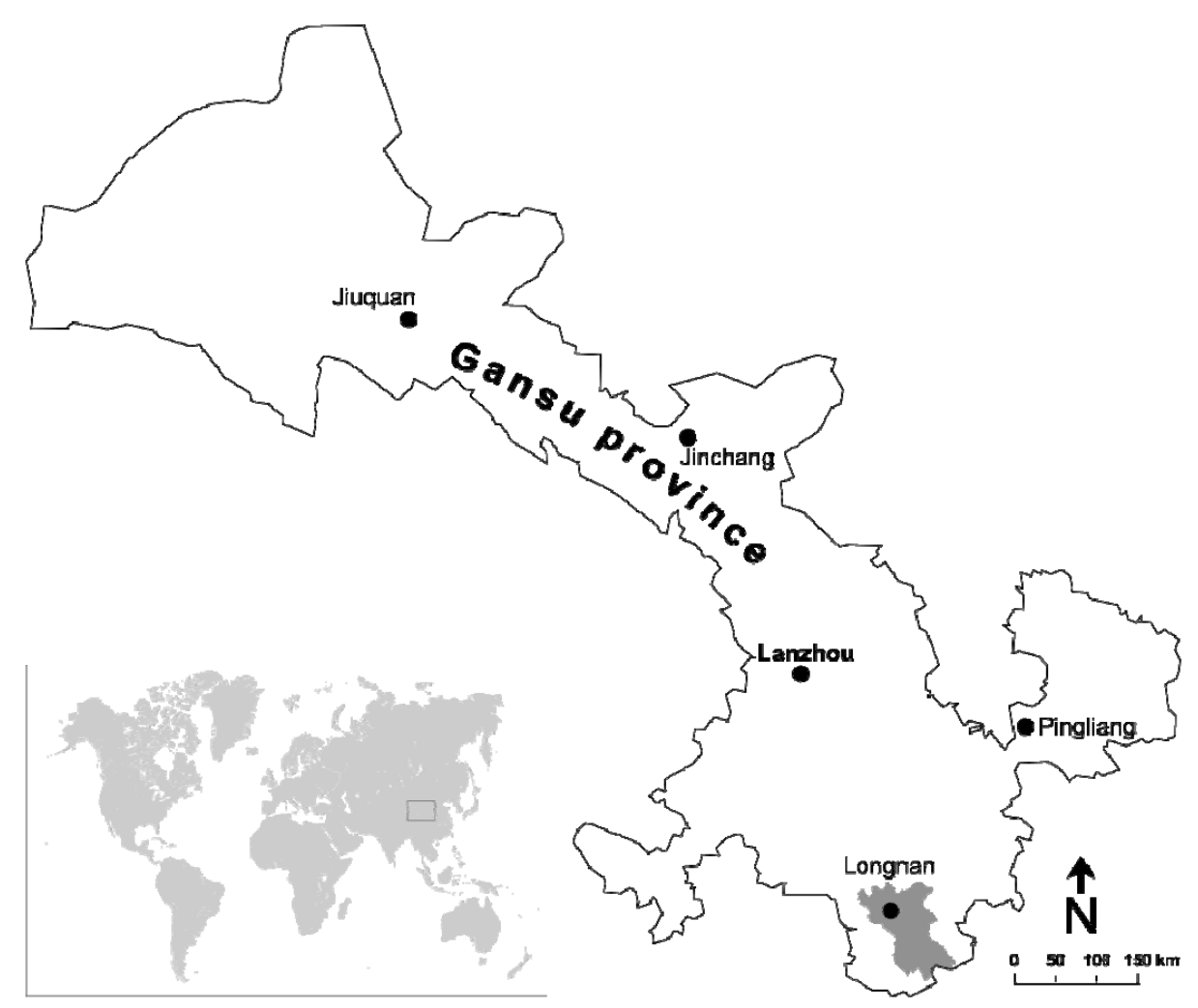

Figure 1 Location of the Wudu region (grey area) in southern Gansu province, China

The steep slopes of this rural region are often terraced and are used for agriculture. The Wudu region belongs to the drainage system of Bailongjiang river which is a tributary of the Yangtze (Changjiang) river. The area is influenced by warm and humid subtropical monsoon climate and experiences orographical effects due to the mountainous topography. Thus, climatic conditions vary strongly with elevation and topographical position. Regional governmental agencies use simple, empirical rule of thumb (Chen et al., 2006) to roughly estimate the annual precipitation for different elevations; altitudes below $1500 \mathrm{~m}$ receive approximately $400 \mathrm{~mm}$ per year, while elevation between 1500 and $2000 \mathrm{~m}$ receive an annual rainfall of 500 to $600 \mathrm{~mm}$, and elevation above $2000 \mathrm{~m}$ experience more than $600 \mathrm{~mm}$ of rainfall each year. The annual rainfall distribution shows a significant peak during summer (May to September), when approximately $80 \%$ of the annual rainfall is recorded. Rainfall events usually have durations of several days, but also short events with high intensity (up to $40 \mathrm{~mm}$ per hour) occur.
The combination of high relative relief, steep slopes and weak lithology, as well as the triggering influence of strong monsoonal rainfall and frequent earthquakes result in both large localised slope failures and widespread landslide occurrences. The Wudu region has long been known to be extremely prone to landslides and been rated as one of China's most severely landslide-affected regions (Scheidegger and $\mathrm{Ai}$, 1987). According to the landslide classification by Cruden and Varnes (1996), the landslides in the Wudu region are mostly translational and rotational slides of loess and colluvial material which in some cases have a flow type run-out. Earthquakes and human activities (e.g. slope cutting and irrigation) have frequently triggered landslides but in particular rainstorm events have been reported to be of major importance for landslide triggering, with $95 \%$ of the landslides occurring in the rainy season from May to September and the more than half of all landslides occurring in August and September (Chen et al., 2006). In addition, $60 \%$ of all recorded slope failures took place in years of annual rainfall above average. 
Widespread landslide activity was particularly observed in the 1980s. In 1982, eight times more landslides than on average occurred as a consequence of heavy rainstorms in that year. Another significant event took place on August 3, 1984, when heavy rainfall caused more than 400 debris flows and 570 landslides which together affected approximately 9.3 million people and caused a direct economic loss of 265.26 million Yuan (approximately 30 million Euro) (Chen et al.,
2006). Over the last four decades at least 567 people were killed by landslides in the Wudu region (China Geological Survey Bureau of Statistics, 2008). One of the most recent destructive landslide events that was also reported in international news took place on August 8, 2010, in Zhouqu County, where a fast moving debris flow swept through the city destroying large areas and claimed at least 1287 lives (Yu et al., 2010).

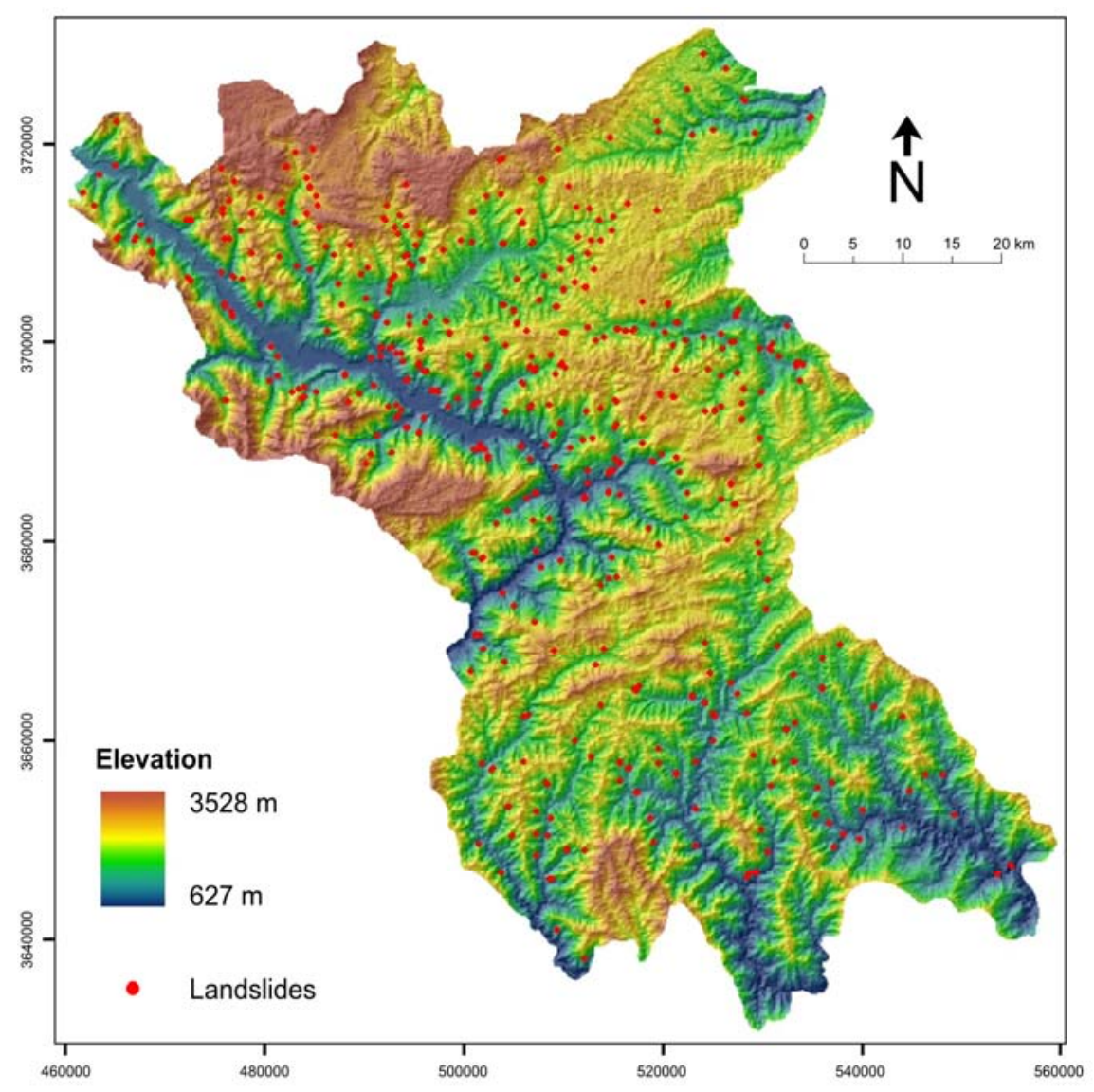

Figure 2 Distribution of rainfall-triggered landslides in the period from 1995 to 2003 in the Wudu region

\section{Generation of input data}

\subsection{Historical rainfall-triggered landslide inventory}

The 'Ministry of Land and Resources of the People's Republic of China' has been working on geo-hazard survey plans in counties seriously affected by geohazards since 1999. The 'Longnan First Station for
Landslide and Debris Flow Forecasting and Warning System of the Upper Reaches of the Yangtze River' was constructed in 1991. Both institutes provided information on landslide occurrences which were used to derive an inventory of rainfall-induced landslides between 1995 and 2003 for the Wudu region. The recorded attributes include spatial characteristics (location, length, width, volume), temporal information (day of failure), damage 
information (people affected, damage caused) and additional information (e.g. landslide type and triggering conditions). For the period between 1995 and 2002, a total number of 217 rainfall-triggered landslides were recorded. In 2003 alone, 290 landslides and 360 debris flows triggered by seven rainfall events are listed. In total, 507 landslides are contained in the inventory (Fig. 2).

\subsection{Landslide causative factors}

Topographical information in the form of a digital elevation model (DTM) with a pixel size of $30 \times 30 \mathrm{~m}$ was created by digitising a 1:50,000 topographical map. Subsequently, all other spatial input data was set to the same pixel size independent of the scale of the original data source. The DTM was also used to derive topographical characteristics such as elevation, slope angle and aspect using ArcGIS tools. Rivers and roads were digitised manually from the topographical map. Information on lithology was available in the form of the geological map (1:200,000) which was reclassified (Chen et al., 2006) to cluster eight lithological units which have similar physical-mechanical characteristics (Fig. 3).
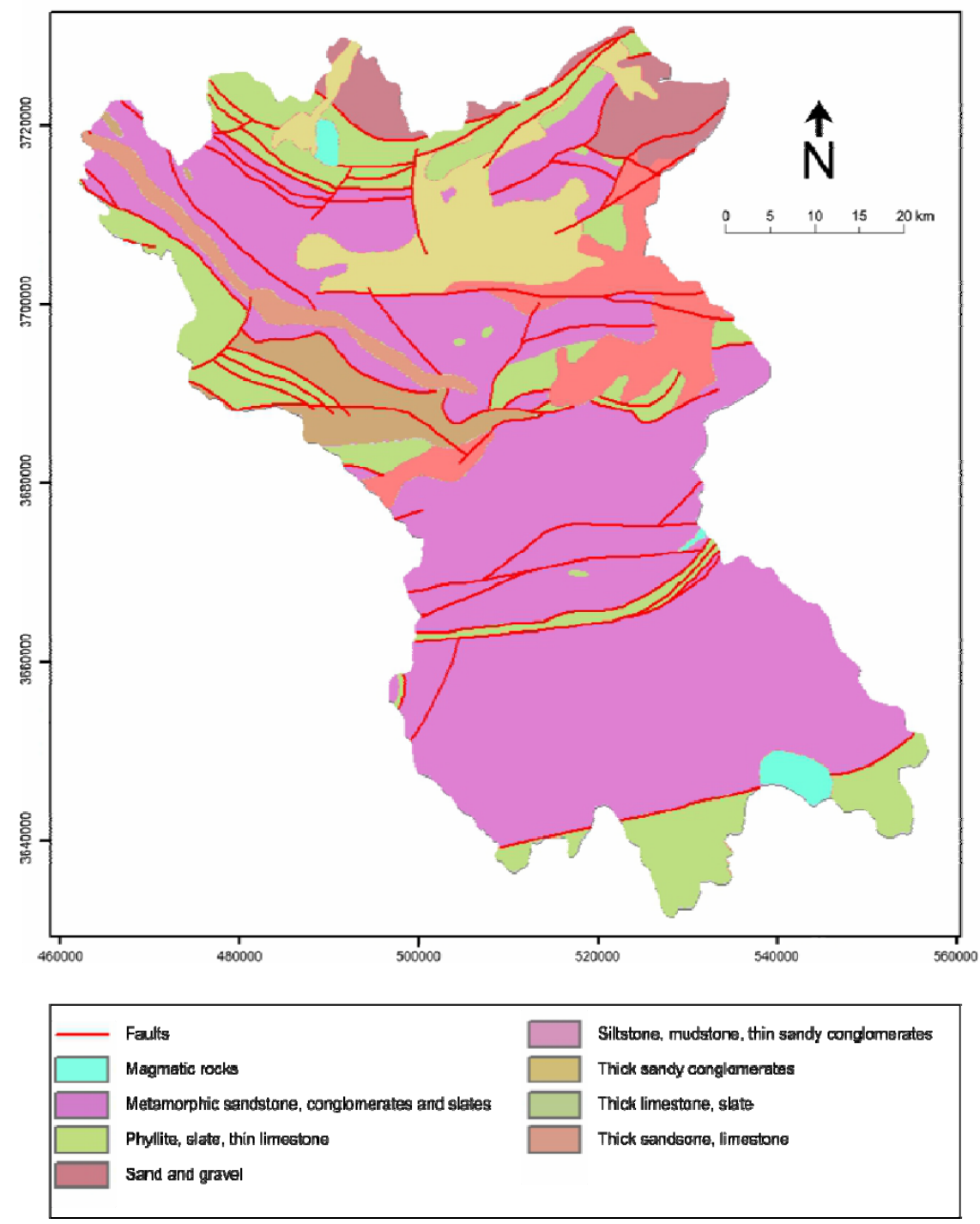

Figure 3 Lithological units and faults in the Wudu region (based on the 1:200,000 geology map) (modified after Bai et al. 2013b) 
Land use types were mapped using pre-processed Landsat MSS, TM and ETM images (Liu et al., 2003; $\mathrm{Wu}$ et al., 2004). After geometrical correction and georeferencing of the images, the average location errors were found to be less than $50 \mathrm{~m}$ (about 2 pixels). The accuracy of the landuse interpretation was validated in the field by random checks and resulted in an accuracy of the land-use classification of 92.9\% (Liu et al., 2003). An annual average rainfall (1971-2009) map based on the data from 16 stations of which 9 are located within the study area were available to this study. The data from the respective stations were used for a spatial interpolation of annual precipitation using the kriging function (linear variogram model) in ArcGIS. Orographic effects of topography on rainfall distributions were not taken into account. In addition, daily rainfall measurements from five weather stations for the period from 1995 to 2003 were available and used to estimate the antecedent rainfall conditions of landslides in the study area.

\section{Spatial-temporal landslide analyses}

\subsection{Spatial landslide analysis}

In this study, the results of a logistic regression analysis of spatial landslide susceptibility were used (Bai et al., 2013a). The algorithm of logistic regression applies a maximum likelihood estimation after a transformation of the dependent variable into a logic variable, which is representing the natural log of the odds of the dependent variable occurring or not. In this way, the logistic regression estimates the probability of a certain event occurring (Atkinson and Massari, 1998). In this study, the dependent variable is a binary variable representing the presence or absence of landslides. The logistic model can be expressed in its simplest form as:

$$
P=\frac{1}{1+e^{-z}}
$$

where, $P$ is the probability of an event (landslide) occurrence, which varies from 0 to 1 on an s-shaped curve; $z$ is defined as the following equation (linear logistic model), and its value varies from $-\infty$ to $+\infty$ :

$$
z=\hat{\beta}_{o}+\hat{\beta}_{1} X_{1}+\hat{\beta}_{2} X_{2}+\ldots+\hat{\beta_{n}} X_{n}
$$

Where $\hat{\beta}_{0}$ is the intercept of the model, $n$ is the number of independent variables, $\hat{\beta}_{i}(i=1,2,3$, $\ldots, n)$ is the slope coefficient of the model, and $x_{i}(i=$ $1,2,3, \ldots, n)$ is the independent variable. The linear model formed shows the relation of the dependent variable (presence of a landslide (1) or the absence (0) of a landslide) and the independent variables (pre-failure conditions) (Bai et al., 2010b).

The landslide susceptibility mapping by the logistic regression model includes five main steps: (1) sampling of the data set; (2) splitting of the dataset by random selection into a calibration and validation sub-set; (3) multi-collinearity diagnosis by an analysis of the tolerance (TOL) and variance inflation factor (VIF); (4) application of logistic regression model; and (5) validation and evaluation of the model results by calculating the receiveroperating characteristics (AUROC).

For the landslide susceptibility analysis all 507 rainfall-triggered landslides were used. In total, 507 landslide and 507 non-landslide points were randomly selected. Input variables included topographical factors (elevation, slope angle, aspect), lithological classes, land use classes and spatially interpolated annual average precipitation (1971-2009). Categorised parameters such as lithology and land use were first transformed into a numerical variable (dummy variable) before they were included into the logistic regression model.

\subsection{Temporal landslide analysis}

In this study, the results of a landslide triggering rainfall threshold analysis were used (Bai et al., 2013b). Critical rainfall conditions were determined by applying the antecedent daily rainfall model in combination with logistic regression to estimate landslide occurrence probabilities. This model is based on the research of Crozier and Eyles (1980), Crozier (1999), and Glade et al. (2000) and represents a conceptual approach to rainfall thresholds which are estimated based on soil 
moisture conditions. A soil water status index is calculated based on the daily rainfall, and a decay factor which accounts for the loss of water due to evaporation and drainage from the soil over a period of days prior to a landslide event. The antecedent daily rainfall model was applied to the landslides triggered by the 2003 rainfall events in the Wudu region. From the available five meteorological stations, the highest daily precipitation records were assumed to be the triggering rainfall for the respective landslides. Due to missing local soil information, the decay constant $k$ (representing the outflow of the regolith) was set to 0.84 and the $r_{n}$ (maximum regional precipitation on the $n^{\text {th }}$ day before 0 ) to 10 days. This value was chosen after initial analysis of rainfall data and is the same as in other studies (Crozier and Eyles, 1980; Aleotti, 2004). For the calculation of probability thresholds, days with landslide occurrences were treated as a binary variable. By a logistic regression, the correlation between the dependent variable (landslide occurrence) and the independent variables (antecedent daily rainfall $r_{a}$ and daily rainfall at the day of slope failure $r_{0}$ ) was determined.

\subsection{Combined spatio-temporal landslide analysis}

In order to facilitate spatio-temporal landslide analyses, we adopted a simple matrix to combine the calculated spatial and temporal landslide probabilities. Thereto, the susceptibility map was classified into four equal interval classes, i.e. level 1 (very low susceptibility), level 2 (low susceptibility), level 3 (medium susceptibility) and level 4 (high susceptibility). Break points for the classes were chosen to be $0.25,0.5$ and 0.75 . Similarly, the daily occurrence probabilities derived from both daily precipitation and antecedent rainfall were divided into four classes based on the daily landslide probability, i.e. level 1 (very low probability; $<0.08$ ), level 2 (low probability; 0.08-0.17), level 3 (medium probability; 0.17-0.58) and level 4 (high probability; $>0.58$ ). The combination matrix assigns a high index class to a high landslide susceptibility level and a high level of failure probability. In contrast, a low landslide susceptibility level and low landslide occurrence probability level result in a low combined spatio-temporal index value. A very high spatial landslide probability combined with a low temporal probability results in the combined spatiotemporal class 2, and vice versa (Table 1 ). The combination of landslide susceptibility and occurrence probability was carried out with landslides that were not included in the previous determination of landslide occurrence probabilities and the respective rainfall thresholds. In total, 122 randomly selected landslides that have occurred prior to 2003 were used.

Table 1 Matrix used for combining landslide occurrence probability and susceptibility classes

\begin{tabular}{lllll}
\hline Temporal & \multicolumn{4}{c}{ Spatial probability } \\
\cline { 2 - 5 } probability & Level 1 & Level 2 & Level 3 & Level 4 \\
\hline Level 1 & Class 1 & Class 1 & Class 1 & Class 2 \\
Level 2 & Class 1 & Class 2 & Class 2 & Class 3 \\
Level 3 & Class 1 & Class 2 & Class 3 & Class 4 \\
Level 4 & Class 2 & Class 3 & Class 4 & Class 4 \\
& & & &
\end{tabular}

\section{Results}

\subsection{Susceptibility mapping}

The application of the logistic regression model to estimate spatial landslide susceptibility resulted in a map (Fig. 4). High susceptibility classes can be found in the north-western part of the study area where the highest elevations and steepest slopes are present. The statistical analysis (Bai et al., 2013a) of the influence of each variable showed that besides topographical aspects (primarily slope angle) lithological conditions control the spatial distribution of landslides. Herein, mudstone, siltstone and conglomerates are the most susceptible lithological units. In total, $46 \%$ of the rainfall triggered landslides are located in the highest susceptibility class, while $39 \%$ are within the class of medium landslide susceptibility. Analysis of the VIF and TOL showed values of less than 2 and more 0.4 , respectively. The validation of the susceptibility map was carried out by analysing the prediction rate curves (Van Den Eeckhaut et al., 
2009). Results show prediction rates of $70.2 \%$ and $76 \%$ for landslides and non-landslides susceptibility class. The AUC (area under curve) value that represents a quantitative measure of the model performance reached 0.782 , thereby indicating a good model performance (Swets, 1988).

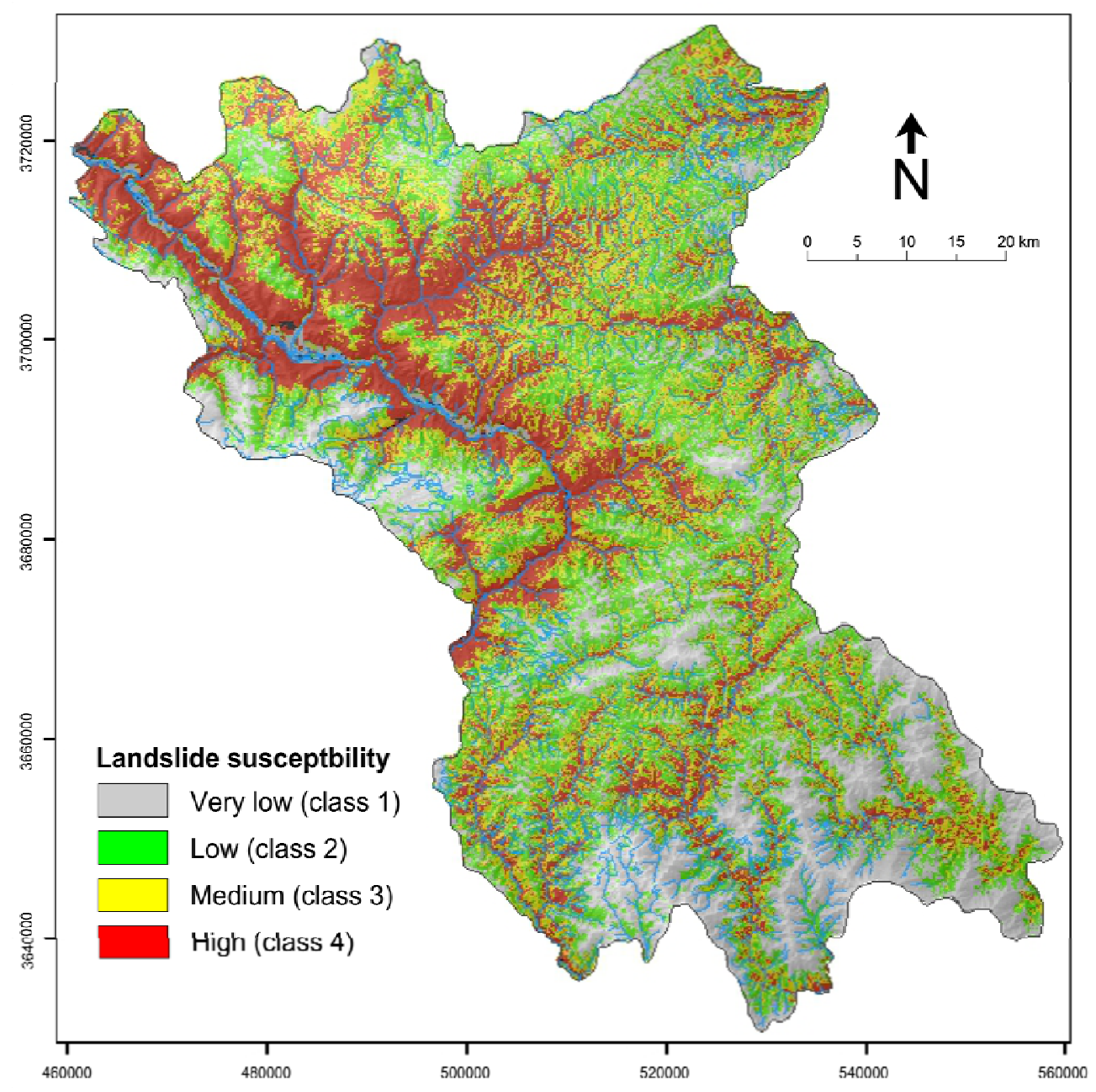

Figure 4 Landslide susceptibility map (modified after Bai et al. 2013a)

\subsection{Landslide occurrence probability}

The probability of failure as a consequence of daily and 10-day antecedent rainfall can be expressed by the following equation:

$$
\log \left(\frac{p}{1-p}\right)=-5.26+0.22 r_{0}+0.31 r_{a}
$$

where, $p$ is the landslide occurrence probability at day 0 (i.e. the day of failure), $r_{0}$ the daily precipitation at day 0 , and $r_{a}$ the the antecedent daily precipitation for a specified period prior to day 0 (here 10 days). The respective equation demonstrates the triggering conditions for landslides in the Wudu region based on the combination of 10-day antecedent precipitation and the daily rainfall (Fig. 5). In general, lower daily rainfall is required when higher antecedent rainfall conditions are present. After a certain threshold of antecedent rainfall the soil is so saturated, that no daily rainfall is required to cause landslides. Thus such an initiation is purely based on internal factors (such as positive pore water pressures) and not on external forces (such as additional precipitation). The results indicate, that a 10-day antecedent rainfall index of $20 \mathrm{~mm}$ is related to a $90 \%$ probability of landslides in the study area even 
without any additional rainfall on the same day. The probability decreases to $50 \%$ and $10 \%$ with $17 \mathrm{~mm}$ and $13 \mathrm{~mm}$, respectively. Similarly, an exceedance of a daily rainfall index value of $28 \mathrm{~mm}$ is related to a
$90 \%$ probability of slope failures even without any antecedent rainfall. This probability decreases to $10 \%$ with a daily rainfall of $19 \mathrm{~mm}$.

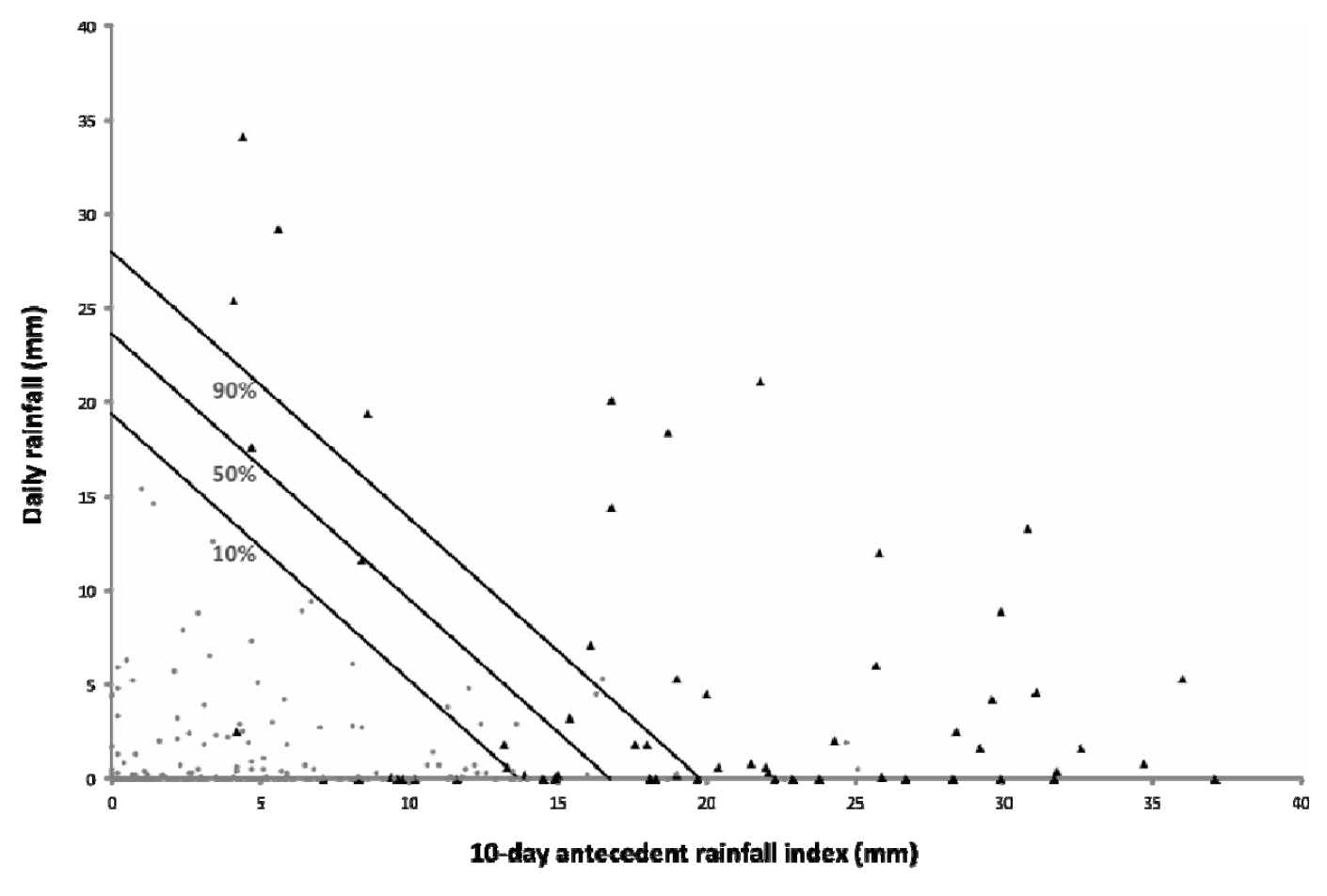

$\Delta$ landslide event no landslide event

Figure 5 Rainfall thresholds for the Wudu region and related landslide occurrence probabilities (Bai et al. 2013b)

\subsection{Spatio-temporal landslide analyses}

A total of 122 landslides that have occurred between 1995 and 2002 were randomly selected for the creation of combined spatio-temporal landslide maps (Fig. 6) illustrating potential landslide scenarios for certain rainfall events. The daily rainfall model was applied to the selected landslides which relate to rainfall conditions that have a low, medium and high probability of causing slope failures; none fell into the category of very low occurrence probability (Fig. 6A). Figure 6B displays the spatiotemporal landslide map for rainfall conditions that have low probability of triggering landslides. Due to the re-classification using the matrix (Table 1), only very low, low and medium classes are present. This map can be interpreted as the baseline susceptibility where areas are identified that might suffer landslides under frequently occurring rainfall conditions. Figure $6 \mathrm{C}$ is based on rainfall events with a medium probability to cause landslides. The spatial classification is the same as for the general susceptibility map (Fig. 4). Such rainfall conditions can be expected to occur regularly. The worst-case scenario is presented in Figure 6D. Under rainfall conditions that are related to a high probability of landslides, the susceptibility is much higher than in the previous maps. Large sections of the steep lower slopes in the study area have a high susceptibility and are thus likely to fail during extreme rainfall conditions. 

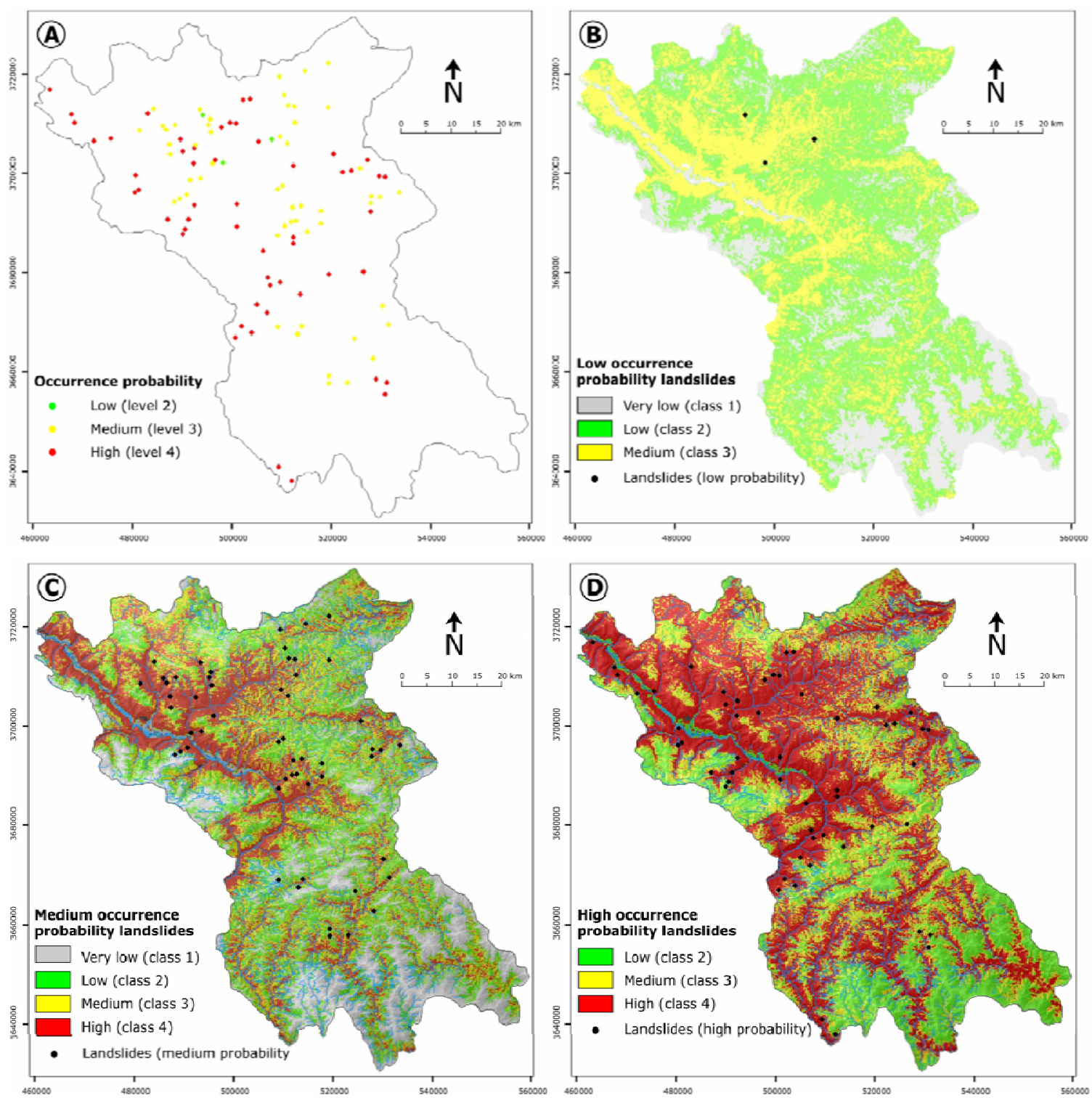

Figure 6 Position and occurrence probabilities of landslides (A); spatio-temporal landslide maps for landslides for low (B), medium (C) and high (D) occurrence probability

\section{Discussion}

This study presents the combination of spatial and temporal landslide probabilities using a matrix approach. The landslide susceptibility map and the temporal landslide occurrence probability were estimated by well established methodologies, i.e. logistic regression and the daily antecedent rainfall model. The susceptibility map highlights the extreme landslide proneness of the area with its high and steep mountain slopes which consist of weak lithological units. The rainfall thresholds show that both daily and antecedent rainfall play an important role for landslide triggering, however, daily rainfall has a larger influence. In comparison to other study areas, it was found that rainfall thresholds are relatively low (see http://rainfallthresholds.irpi.cnr.it/ for an extensive selection of rainfall thresholds); however, they are in good agreement with the conditions observed in the Wudu region. 
The susceptibility map and rainfall thresholds could already be used to raise awareness among the general public as well as to support regional decision-makers on risk management and spatial planning. In general, temporal and spatial landslide probabilities are regarded as separate products; in this study, however, an innovative approach is proposed in which a matrix is used to combine the aforementioned landslide probabilities, and to assign a combined spatio-temporal index value to the land surface. The resulting map therefore combines information on the environmental factors predisposing the area to landslides, as well as information on the triggering rainfall conditions. We are convinced that the combined spatio-temporal landslide maps better highlight the hot-spots of potential landslide activity and represent an added value to the use of susceptibility maps or rainfall thresholds alone. A particular strength of the proposed method is the scenario building which can be thought of as a representation of the outcomes of specific rainfall events. For areas, which feature a medium probability of failure under frequently occurring rainfall conditions, even small rainfall events can be expected to lead to scattered slope failures. The worst-case scenario map that shows susceptibility conditions for extreme rainfall events can be used to estimate the outcomes of rare storms causing widespread slope failures. Such scenarios could help to improve the communication of regional stakeholders and the general public by raising awareness towards the landslide hazards.

To improve the results of the presented research, further investigations of landslidetriggering rainfall conditions should be carried out. Currently, the antecedent daily rainfall is calculated by a simple decay factor which simplifies the storage of water in soils. Internal characteristics of soils, such as permeability and saturated soil water content, as well as external factors such as evapotranspiration are not reflected. Moreover, only limited rainfall data was available to this study. Additional weather stations and complex simulations of rainfall distributions including orographic effects of topography would help to calculate more precise landslide-triggering rainfall thresholds. Moreover, additional data for the calculation of spatial landslide probabilities, in particular digital elevation data of higher resolution than the current $30 \mathrm{~m}$ pixels, would be desirable and could drastically improve the results of susceptibility modelling. It also must be questioned in which extent the rainfall thresholds and the susceptibility maps are valid for the future given that they are only based on a short period for which data were available and due to the fact that the ongoing economic growth in Western China leads to massive human impacts, such as land use changes, increased population pressure and large scale construction of infrastructures.

Table 2 Three examples of possible matrixes for deriving spatio-temporal index values. (a) matrix assigning fewer low probability index values; (b) matrix assigning more low probability index values; (c) matrix introducing a fifth probability class to highlight hot-spots

\begin{tabular}{|c|c|c|c|c|c|}
\hline \multirow[t]{2}{*}{ (a) } & \multirow{2}{*}{$\begin{array}{l}\text { Temporal } \\
\text { probability }\end{array}$} & \multicolumn{4}{|c|}{ Spatial probability } \\
\hline & & Level 1 & Level 2 & Level 3 & Level 4 \\
\hline & Level 1 & Class 1 & Class 1 & Class 2 & Class 2 \\
\hline & Level 2 & Class 1 & Class 2 & Class 2 & Class 3 \\
\hline & Level 3 & Class 2 & Class 2 & Class 3 & Class 4 \\
\hline & Level 4 & Class 2 & Class 3 & Class 4 & Class 4 \\
\hline \multirow[t]{6}{*}{ (b) } & Temporal & \multicolumn{4}{|c|}{ Spatial probability } \\
\hline & probability & Level 1 & Level 2 & Level 3 & Level 4 \\
\hline & Level 1 & Class 1 & Class 1 & Class 1 & Class 1 \\
\hline & Level 2 & Class 1 & Class 2 & Class 2 & Class 2 \\
\hline & Level 3 & Class 1 & Class 2 & Class 3 & Class 3 \\
\hline & Level 4 & Class 1 & Class 2 & Class 3 & Class 4 \\
\hline \multirow[t]{6}{*}{ (c) } & Temporal & \multicolumn{4}{|c|}{ Spatial probability } \\
\hline & probability & Level 1 & Level 2 & Level 3 & Level 4 \\
\hline & Level 1 & Class 1 & Class 1 & Class 2 & Class 2 \\
\hline & Level 2 & Class 1 & Class 3 & Class 3 & Class 3 \\
\hline & Level 3 & Class 2 & Class 3 & Class 4 & Class 4 \\
\hline & Level 4 & Class 2 & Class 3 & Class 4 & Class 5 \\
\hline
\end{tabular}


We think that a matrix approach is very useful for the combination of spatial and temporal landslide probabilities, however, it must be noted that it is of course extremely sensitive to the classification of the input data. Classifications for both, susceptibility maps and rainfall thresholds may greatly vary from one study to another and no single classification standard exists. Instead, the classification is generally defined based on the goal of the study or the requirements of the user group for which it is prepared. More complex classification could be appropriate for experienced spatial planners while the general public could probably benefit more from more simple map products. Some possible matrixes to be used in future studies are visualised in Tables 2 .

\section{Conclusions}

This study presents an innovative approach to carry out a semi-quantitative analysis of spatio-temporal landslide probabilities in the Wudu study area in western China. Based on a database on landslide causative factors and an inventory of historic slope failures, a susceptibility map is calculated by a GISbased logistic regression which ranks areas according to their likelihood to produce slope failures. In particular areas with mudstones, siltstone and conglomerates on slopes steeper than $20^{\circ}$ feature a high probability of failure. Landslide occurrence probabilities in relation to daily and antecedent rainfall are estimated using the antecedent daily rainfall model. Rainfall thresholds are relatively low and a $90 \%$ probability of landslides is given with a daily rainfall of $28 \mathrm{~mm}$. A simple yet innovative and adaptable matrix-based methodology is applied to combine the spatial and temporal probabilities of landslides and to produce combined spatio-temporal landslide maps. Therein, the combination of areas of high spatial and temporal probabilities result in high combined index values, while the combination of low spatial and temporal probabilities results in low combined index values. A high spatial landslide probability combined with a low temporal probability results in a medium combined index value, and vice versa. Still, other matrix classification could be used to meet the requirements of the users. The maps produced aim to raise awareness towards landslides hazards and to support regional decision. It can be expected that other researchers will apply a similar methodology to combine temporal and spatial landslide probabilities which are currently mostly put forward separately.

\section{Acknowledgements}

This study was supported by 2015 Jiangsu provincial key R \& D Program (Social Development) (BE2015704), the ESA-MOST Dragon 4 Cooperation Program (32365), the Opening Fund of Key Laboratory of Mountain Surface Process and Hazards of Chinese Academy of Sciences (KLMHESP-17-07), the Opening Fund of Key Laboratory for Geo-hazards in Loess areas (GLA2014005), the Geological survey project of China Geological Survey (DD20160276), and the Priority Academic Program Development of Jiangsu Higher Education Institutions (164320H101).

\section{References}

AdaptAlp Project, 2011. WP 5 Hazard Mapping Summary. ftp://iacftp.ethz.ch/pub_read/bothomas/AdaptAlp/fin al/WP5\%20Summary.pdf

Akgün A, Bulut F. 2007. GIS-based landslide susceptibility for Arsin-Yomra (Trabzon, North Turkey) region. Environmental Geology, 51(8): 1377-1387.

Aleotti P. 2004. A warning system for rainfall-induced shallow failures. Engineering Geology, 73(3-4): 247-265.

Atkinson PM, Massari R. 1998. Generalised linear modelling of susceptibility to landsliding in the Central Apennines, Italy. Computer and Geosciences, 24(4): 373-385.

Bai S, Cheng C, Wang J, Thiebes B, Zhang Z. 2013a. Regional scale rainfall- and earthquake-triggered landslide susceptibility assessment in Wudu County, China. Journal of Mountain Science, 10(5): 743-753.

Bai S, Wang J, Thiebes B, Cheng C, Yang Y. 2013b. Analysis of the relationship of landslide occurrence with rainfall: a case study of Wudu County, China. Arabian Journal of Geosciences, [Accessed: 24 June 2013] http://link.springer.com/10.1007/s12517-013-0939-9.

Bai S, Wang J, Zhang Z, Cheng C. 2012. Combined landslide susceptibility mapping after Wenchuan 
earthquake at the Zhouqu segment in the Bailongjiang Basin, China. Catena, 99: 18-25.

Bai SB, Wang J, Glade T, Bell R, Thiebes B. 2010a. Rainfall threshold analysis and landslide susceptibility mapping in Wudu county. In: Proceedings of the Second World Landslide Forum. Rome, Italy.

Bai SB, Wang J, Lu GN, Zhou PG, Hou SS, Xu SN. 2009. GIS-Based and Data-Driven Bivariate LandslideSusceptibility Mapping in the Three Gorges Area, China. Pedosphere, 19(1): 14-20.

Bai SB, Wang J, Lü GN, Zhou PG, Hou SS, Xu SN. 2010b. GIS-based logistic regression for landslide susceptibility mapping of the Zhongxian segment in the Three Gorges area, China. Geomorphology, 115 (1-2): 23-31.

Bell FG, Maud RR. 2000. Landslides associated with the colluvial soils overlying the Natal Group in the greater Durban region of Natal, South Africa. Environmental Geology, 39(9): 1029-1038.

Bell R, Cepeda J, Devoli G. 2014. Landslide susceptibility modeling at catchment level for improvement of the landslide early warning system in Norway. In: Proceedings of World Landslide Forum 3. June 2-6, 2014, Beijing.

Bundesamt für Umwelt Wald und Landschaft, 1998. Methoden zur Analyse und Bewertung von Naturgefahren. Umwelt-Materialien 85.

Caine N. 1980. The Rainfall Intensity: Duration Control of Shallow Landslides and Debris Flows. Geografiska Annaler. Series A, Physical Geography, 62(1/2): 23-27.

Canuti P, Focardi P, Garzonio CA. 1985. Correlation between rainfall and landslides. Bulletin of the International Association of Engineering Geology, 32: 49-54.

Capparelli G, Biondi D, De Luca DL, Versace P. 2009. Hydrological and complete models for forecasting landslides triggered by rainfalls. In: Rainfall-induced landslides. Mechanisms monitoring techniques and nowcasting models for early warning systems. Proceedings of the 1st Italian Workshop on Landslides. pp. 8-10.

Cepeda J, Höeg K, Nadim F. 2010. Landslide-triggering rainfall thresholds: A conceptual framework. Quarterly Journal of Engineering Geology and Hydrogeology, 43(1): 69-84.

Chen WW, Zhai ZF, Liu G, Liang SY. 2006. The engineering geological problems of the Gansu section of Lanzhou-Haikou highway. Lanzhou University Press, Lanzhou.

Chigira M, Wu X, Inokuchi T, Wang G. 2010. Landslides induced by the 2008 Wenchuan earthquake, Sichuan, China. Geomorphology, 3-4(118): 225-238.
China Geological Survey Bureau of Statistics, 2008. China Geological Environment InfoNet [online]. Geological Bulletin of China. [Accessed: 23 May 2009] http://www.cigem.gov.cn/defaulteng.html

Chleborad AF, Baum RL, Godt JW, Powers PS. 2008. A prototype system for forecasting landslides in the Seattle, Washington, area. Reviews in Engineering Geology,103-120, reg.gsapubs.org/cgi/doi/10.1130/2008.4020(06)

Chowdhury R, Flentje P. 2003. Role of slope reliability analysis in landslide risk management. Bulletin of Engineering Geology and the Environment, 62(1): 4146.

Cigna F, Bianchini S, Casagli N. 2012. How to assess landslide activity and intensity with Persistent Scatterer Interferometry (PSI): the PSI-based matrix approach. Landslides. http://www.springerlink.com/index/10.1007/s10346012-0335-7 [Accessed: 13 July 2012]

Corominas J, Moya J. 1999. Reconstructing recent landslide activity in relation to rainfall in the Llobregat River basin, Eastern Pyrenees, Spain. Geomorphology, 30(1-2): 79-93.

Crosta GB, Frattini P. 2008. Rainfall-induced landslides and debris flows. Hydrological Processes, 22(4): 473-477.

Crozier MJ. 1999. Prediction of rainfall-triggered landslides: a test of the antecedent water status model. Earth Surface Processes and Landforms, 24(9): 825-833.

Crozier MJ, Eyles RJ. 1980. Assessing the probability of rapid mass movement. In: Proceedings of the $3 \mathrm{rd}$ Australia and New Zealand conference on Geomechanics. New Zealand Institute of Engineers, pp. 247-251.

Cruden DM, Varnes DJ. 1996. Landslide types and processes. In: Turner AK, Schuster RL. (eds.): Landslides: Investigation and Mitigation (Special Report). National Research Council, Transportation and Research Board Special Report 247, Washington, D.C., USA, pp. 36-75.

Cui $P$, Chen X-Q, Zhu Y-Y, Su F-H, Wei F-Q, Han Y-S, Liu H-J, Zhuang J-Q. 2009. The Wenchuan Earthquake (May 12, 2008), Sichuan Province, China, and resulting geohazards. Nat Hazards, 56(1): 19-36.

De Graff JV, Romesburg HC, Ahmad R, McCalpin JP. 2012. Producing landslide-susceptibility maps for regional planning in data-scarce regions. Natural Hazards, 64(1): 729-749.

DeGraff JV, Romesburg C. 1980. Regional landslide susceptibility assessment for wildland management: a matrix approach.

http://digitalcommons.usu.edu/envs_facpub/50/

[Accessed: 30 July 2015] 
Derbyshire E, Wang JT, Meng X. 1999. The environment: geology, geomorphology, climate and land use. In: Derbyshire E, Meng XM, Dijkstra TA. (eds.): Landslide in the thick loess terrain of north-west China. Wiley, pp. 22-46.

Fernández CI, Del Castillo TF, Hamdouni R, El Montero JC. 1999. Verification of landslide susceptibility mapping: a case study. Earth Surface Processes and Landforms, 24: 537-544.

Fernández T, Irigaray C, Hamdouni R, El Chacón J. 2003. Methodology for landslide susceptibility mapping by means of a GIS. Application to the Contraviesa area (Granada, Spain). Natural Hazards, 30(3): 297-308.

Giannecchini R. 2005. Rainfall triggering soil slips in the southern Apuan Alps (Tuscany, Italy). Advances in Geosciences, 2: 21-24.

Glade T. 2000. Applying Probability Determination to Refine Landslide-triggering Rainfall Thresholds Using an Empirical Antecedent Daily Rainfall Model. Pure and Applied Geophysics, 157(6-8): 1059-1079.

Greco R, Sorriso-Valvo M, Catalano E. 2007. Logistic Regression analysis in the evaluation of mass movements susceptibility: The Aspromonte case study, Calabria, Italy. Engineering Geology, 89(1-2): 47-66.

Guzzetti F, Peruccacci S, Rossi M, Stark CP. 2008. The rainfall intensity-duration control of shallow landslides and debris flows: an update. Landslides, 5(1): 3-17.

Huang R, Li W. 2009. Development and distribution of geohazards triggered by the 5.12 Wenchuan Earthquake in China. Sci. China Ser. E-Technol. Sci. 52(4): 810-819.

Innes JL. 1983. Debris flows. Progress in Physical Geography, 7:469-501.

Irigaray C, Fernández T, Hamdouni R, El Chacón J. 2007. Evaluation and validation of landslide-susceptibility maps obtained by a GIS matrix method: examples from the Betic Cordillera (southern Spain). Natural Hazards, 41(1): 61-79.

Jakob M, Holm K, Lange O, Schwab JW. 2006. Hydrometeorological thresholds for landslide initiation and forest operation shutdowns on the north coast of British Columbia. Landslides, 3(3): 228-238.

Jiao Y, Wang D. 2010. Analysis of Geological Changes in Environmental Conditions of Longnan City Triggered by the Earthquake on May 12th. Journal of Gansu Sciences, 22(1): 79-84.

Kjekstad O. 2007. The challenges of landslide hazard mitigation in developing countries. In: First North American Landslide Conference.

Ko Ko C, Flentje P, Chowdhury R. 2004a. Landslides qualitative hazard and risk assessment method and its reliability. Bull Eng Geol Environ, 63(2), http://springerlink.metapress.com/openurl.asp?genre = article\&id =doi:10.1007/s10064-004-0231-z

Ko Ko C, Flentje P, Chowdhury R. 2004b. Interpretation of probability of landsliding triggered by rainfall. Landslides, 1(4): 263-275.

Kohler A, Jülich S, Bloemertz L. 2004. Guidelines: risk analysis, a basis for disaster risk management. Deutsche Gesellschaft für Technische Zusammenarbeit (GTZ), Eschborn.

Latelin $\quad$ O. 1997. Berücksichtigung der Massenbewegungsgefahren bei raumwirksamen Tätigkeiten. Bundesamt für Umwelt, Wald und Landschaft.

Liu J, Liu M, Zhuang D, Zhang Z, Deng X. 2003. Study on spatial pattern of land-use change in China during 1995-2000. Science in China Series D: Earth Sciences, 46(4): 373-384.

Lu P, Catani F, Tofani V, Casagli N. 2014. Quantitative hazard and risk assessment for slow-moving landslides from Persistent Scatterer Interferometry. Landslides, 11(4): 685-696.

Matsushi Y, Matsukura Y. 2007. Rainfall thresholds for shallow landsliding derived from pressure-head monitoring: cases with permeable and impermeable bedrocks in Boso Peninsula, Japan. Earth Surface Processes and Landforms, 32(9): 1308-1322.

Paramount Project 2012. Risk Management and Implementation Handbook. Report on the communication and implementation of risk management tools, methods and procedures in the PARAmount test beds (Work Package 8). http://www.alpine-space.org/2007-

2013/projects/projects/detail/PARAmount/show/inde x-2.html\#project_outputs

Petley D. 2012. Global patterns of loss of life from landslides. Geology, 40(10): 927-930.

Raetzo HOL, Bollinger D, Tripet J. 2002. Hazard assessment in Switzerland - Codes of Practice for mass movements. Bulletin of Engineering Geology and the Environment, 61(3): 263-268.

Rossi M, Peruccacci S, Brunetti MT, Marchesini I, Luciani S, Ardizzone F, Balducci V, Bianchi C, Cardinali M, Fiorucci $F$, Mondini AC, Reichenbach $P$, Salvati $P$, Santangelo MA, Bartolini D, Gariano SL, Palladino M, Vessia G, Viero A, Antronico L, Borselli L, Deganutti AM, Iovine $G$, Luino $F$, Parise $M$, Polemio $M$, Guzzetti F, Luciani S, Fiorucci F, Mondini Santangelo N, Tonellid G. 2012. SANF: National warning system for rainfall-induced landslides in Italy. In: Eberhardt $E$, Froese CR, Turner AK, Leroueil S. (eds.): Proceedings of the 11th International \& 2nd North American Symposium on Landslides. Presented at the 
Landslides and Engineered Slopes - Protecting Society through Improved Understanding, Taylor \& Francis, London, pp. 1895-1899.

SafeLand Project, 2010. Deliverable 2.1: Overview of landslide hazard and risk assessment practices. https://www.ngi.no/download/file/5984

Saito H, Nakayama D, Matsuyama H. 2010. Relationship between the initiation of a shallow landslide and rainfall intensity-duration thresholds in Japan. Geomorphology, 118: 167-175.

Scheidegger A, Ai N. 1987. Clay slides and debris flows in the Wudu region. Journal of Soil and Water Conservation, 19-27.

Sengupta A, Gupta S, Anbarasu K. 2009. Rainfall thresholds for the initiation of landslide at Lanta Khola in north Sikkim, India. Natural Hazards, 52(1): 31-42.

Soeters R, Van Westen CJ. 1996. Slope instability recognition, analysis, and zonation. In: Turner AK, Schuster RL. (eds.): Landslides: Investigation and Mitigation (Special Report). National Research Council, Transportation and Research Board Special Report 247, Washington, D.C., USA, pp. 129-177.

Sorriso-Valvo M, Agnesi V, Gulla G, Merrende L, Antronico L, Di Maggio C, Filice E, Petrucci O, Tansi C. 1994. Temporal and spatial occurrence of landsliding and correlation with precipitation time series in Montaldo Uffugo (Calabria) and Imera (Sicilia) areas. In: Casale M, Fantechi R, Flageollet JC. (eds.): Temporal Occurrence and Forecasting of Landslides in the European Community. pp. 825-869.

Süzen ML, Doyuran V. 2004. Data driven bivariate landslide susceptibility assessment using geographical information systems: a method and application to Asarsuyu catchment, Turkey. Engineering Geology, 71(3-4): 303-321.

Swets JA. 1988. Measuring the accuracy of diagnostic systems. Science, 240(4857): 1285-1293.

Thiebes B. 2012. Landslide analysis and early warning systems: Local and Regional Case Study in the Swabian $A / b$, Germany, Springer Theses Series. Springer, $266 \mathrm{p}$.

Thiery Y. 2007. Susceptibilité du Bassin de Barcelonnette (Ales du sud, France) aux "mouvements de versant": cartographie morphodynamique, analyse spatiale et modélisation probabiliste. http://hal.univ-brest.fr/tel00259135v3/document [Accessed: 28 September 2017]

Thiery Y, Malet J-P, Maquaire O. 2006. Statistical and deterministic analysis of landslide hazard. Application to a forested catchment of the South French Alps. http://www.researchgate.net/publication/278704762

Tonkin \& Taylor Ltd, 2006. Natural Hazard Management Research Report. 158 p.

Van Den Eeckhaut M, Reichenbach P, Guzzetti F, Rossi M, Poesen J. 2009. Combined landslide inventory and susceptibility assessment based on different mapping units: an example from the Flemish Ardennes, Belgium. Natural Hazards and Earth System Sciences, 9: $507-521$.

Van Westen CJ, Asch TWJ, Soeters R. 2006. Landslide hazard and risk zonation-why is it still so difficult? Bulletin of Engineering Geology and the Environment, 65(2): 167-184.

Wilson RC, Torikai JD, Ellen SD. 1992. Development of rainfall thresholds for debris flows in the Honolulu District, Oahu, US Geological Survey Open File Report. 45 p.

Wu LX, Sun B, Zhou SL, Huang S-E, Zhao QG. 2004. A new fusion technique of remote sensing images for land use/cover. Pedosphere, 14(2): 187-194.

Yin Y, Wang F, Sun P. 2009. Landslide hazards triggered by the 2008 Wenchuan earthquake, Sichuan, China. Landslides, 6(2): 139-152.

Yu B, Yang YH, Su YC, Wang GF. 2010. Research on the giant debris flow in Zhouqu county, Gansu province, on August 7, 2010. Journal of Engineering Geology, 18(4): 437-448.

Yu YF, Lam J, Siu CK, Pun WK. 2004. Recent advance in Landslip Warning System. In: Recent Advances in Geotechnical Engineering, Proceedings of the Twenty-fourth Geotechnical Division Annual Seminar. Institution of Engineers, Hong Kong, pp. 139-147.

Zêzere JL, Rodriguez ML. 2002. Rainfall thresholds for landsliding in Lisbon Area (Portugal). In: Rybář J, Stemberk J, Wagner P. (eds.): Landslides: proceedings of the First European Conference on Landslides, Prague, Czech Republic, June 24-26, 2002. Taylor \& Francis, pp. 333-338. 